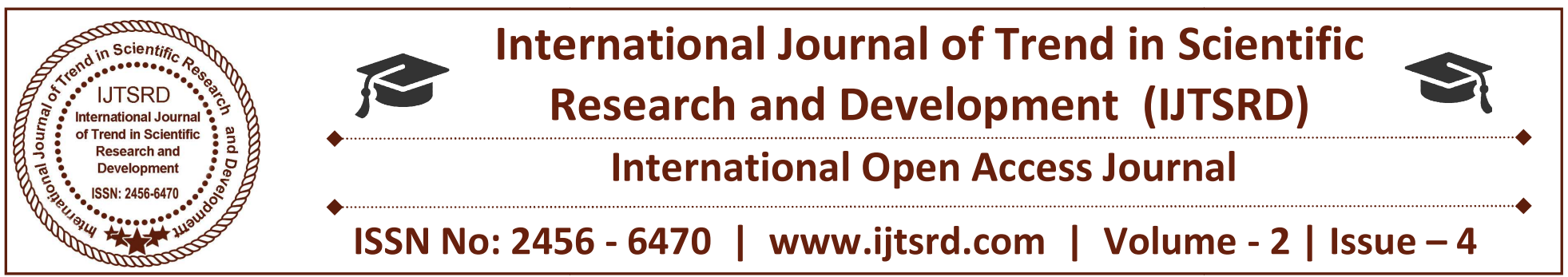

\title{
A Survey: Modernizing Agriculture in India
}

\author{
Naren M S $\mathbf{S}^{1}$, Nishita K Murthy ${ }^{2}$, Manjunath $C \mathbf{R}^{3}$, Soumya $K \mathbf{N}^{4}$ \\ ${ }^{1,2}$ B.Tech Final Year, ${ }^{3}$ Associate Professor, ${ }^{4}$ Assistant Professor \\ $1,2,4$ Department of Information Science \& Engineering, ${ }^{3}$ Department of Computer Science \& Engineering \\ Jain University - School of Engineering \& Technology, Karnataka, India
}

\section{ABSTRACT}

Around $60-70 \%$ of populace in India rely on the Agriculture division. In India, the water management system used in agriculture is obsolete which is causing poor usage of water resources. In some places, faulty techniques are used which results in under-usage or over-usage of water which impacts on the production of crops and decreases the yield. Not only this, proper education or knowledge is not spread to the farmers which will help them increase their production and business by knowing information regarding the soil type and moisture content which is required for a particular crop. Giving modern touch to the agriculture methods is of utmost importance because of the need in agriculture and food for the people to survive. Use of far-reaching and profound technologies such as IoT and cloud computing for modernizing and improving the traditional/ longestablished/ conventional agricultural methods can control the cost, maintenance and provide greater expertise regarding production, quality of seeds, fertilizers, weed, pest control and irrigation. The latest technology like configurable wireless networks, sensors, and other cloud computing resources can be used to build and establish sustainable cloud services for betterment of agriculture.

Keywords: Cloud Computing; Drip irrigation; IoT; Smart Agriculture System; crop monitoring;

\section{INTRODUCTION}

Cloud computing and Internet of Things are the $21 \mathrm{st}$ century's leading-edge technologies. Cloud computing is a method based on Internet to make IT related services such as software and hardware issued to the computers on demand in an easy and clear manner hiding the complexities of those services. India is the biggest manufacturers of milk products, the second biggest manufacturers of rice, wheat, natural products, and vegetables and one of the biggest manufacturers of poultry yet at the same time farmers follow outdated methods for cultivation and its yielding process. This has created a difference in supply and demand chain. This will have an unfavourable impact on farmer's economic status as well as the nation. The qualified services provided by cloud, agriculture and IT to the farmers related to cost, pesticides, fertilizers, crop irrigation, plant disease details, and the various practices of cure used to improvise the field system. The scientists working at $=$ the research and development stations of agriculture are contributing their techniques, suggestions on the modern ideas and strategies for cultivation, fertilizer usage and ploughing methodologies. Based on the information collected such as weather details and soil conditions, precise monitoring and observation on the crop growth can be made using the application process from the crop field.

The qualified services provided by cloud, agriculture and IT to the farmers related to cost,

pesticides, fertilizers, crop irrigation, plant disease details, and the various practices of cure used to improvise the field system. The scientists working at the research and development stations of agriculture are contributing their techniques, suggestions on the modern ideas and strategies for cultivation, fertilizer usage and ploughing methodologies. Based on the 
information collected such as weather details and soil conditions, precise monitoring and observation on the crop growth can be made using the application process from the crop field.

\section{Irrigation in India:}

In India, the cultivated zone comprises of around 36\% of the net sown region. At present, the agrarian division accounts around $83 \%$ of all water usages.

There are different kinds of methods of cultivation activities/practices in various parts of India. Different kinds of cultivation strategies vary in how the water was taken from the source is shared inside the field. All things considered, the goal is to provide the entire field reliably with water, so that each plant has the correct measure of water it requires, neither an overabundance nor insignificantly little.

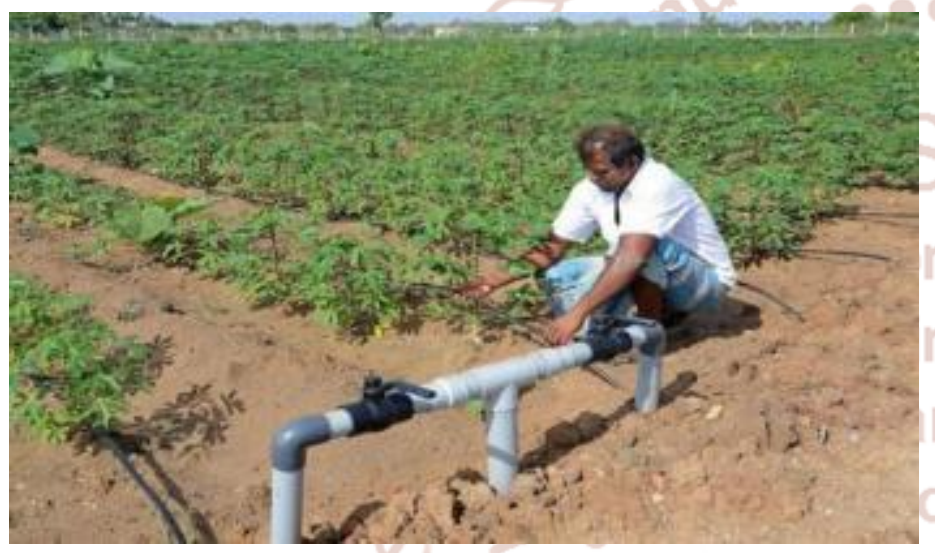

Figure 1.1: Manual Drip Irrigation

Through wells, perennial waterway, trenches, multiple purpose stream valley projects, tanks, etc., cultivation is carried out in India.

\section{Direct Irrigation method:}

In this strategy water is redirected from the stream into the trench by building a deviating structure like weir or flood over the waterway with some pondage to deal it during the day about the differences. It likewise impacts in raising the stream water level which is then ready to stream into the off-taking channel by gravity. The stream in the channel is typically controlled by a gated structure and this in blend with the redirection structure is additionally sometimes called the head works.

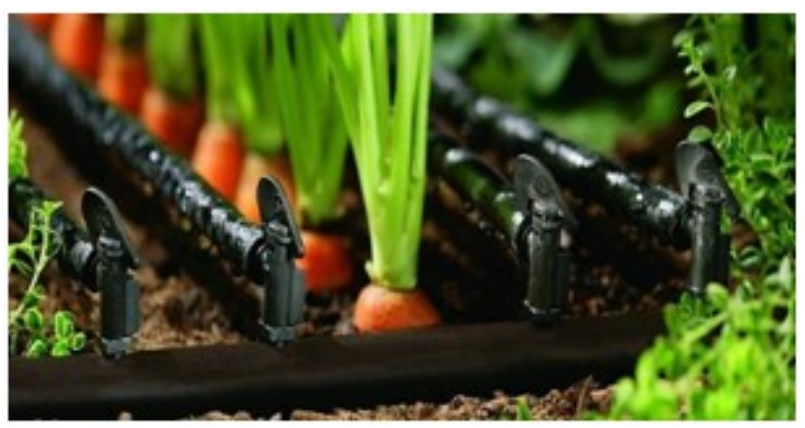

Figure 1.2: Drip Irrigation - Carrots

\section{Storage Irrigation method:}

For this kind of cultivation, some portion of the abundance water of a water stream or a river during the monsoon season which generally would have gone down the stream as a surge is put away in a repository or tank found at the upstream of a dam built over a waterway or river. This collected water is then utilized for cultivation is embraced when the stream of waterway or river is in abundance of the prerequisites of the yield amid a specific period of the year yet falls beneath the necessities or isn't accessible in any way

\section{Background Work}

The various methodologies in agriculture using cloud computing are:

To make use of the Cloud Computing techniques and technologies, a messaging method or system was developed. Along with the Cloud Computing methods, even the devices that were utilized in the system which come in handy were a part of the system. This can be utilized in the field of agriculture so that efficient information management, flexible knowledge and information sharing, local and global communication and production management can be easily accomplished. This eventually brings about an increment and change in the profitability in horticulture and in this way to the economy. Sharing of information and knowledge is very critical for efficient and better productivity in agriculture. This information is maintained by farmers' communities. On the off chance that Cloud Computing is connected in the field of farming proficiently, at that point it will demonstrate to expand general productivity of the field. Moreover, putting away the data in cloud, data administration of a wide range of information identified with the farming land, including area, 
property rights, territory, soil and land qualities can be incorporated [1].

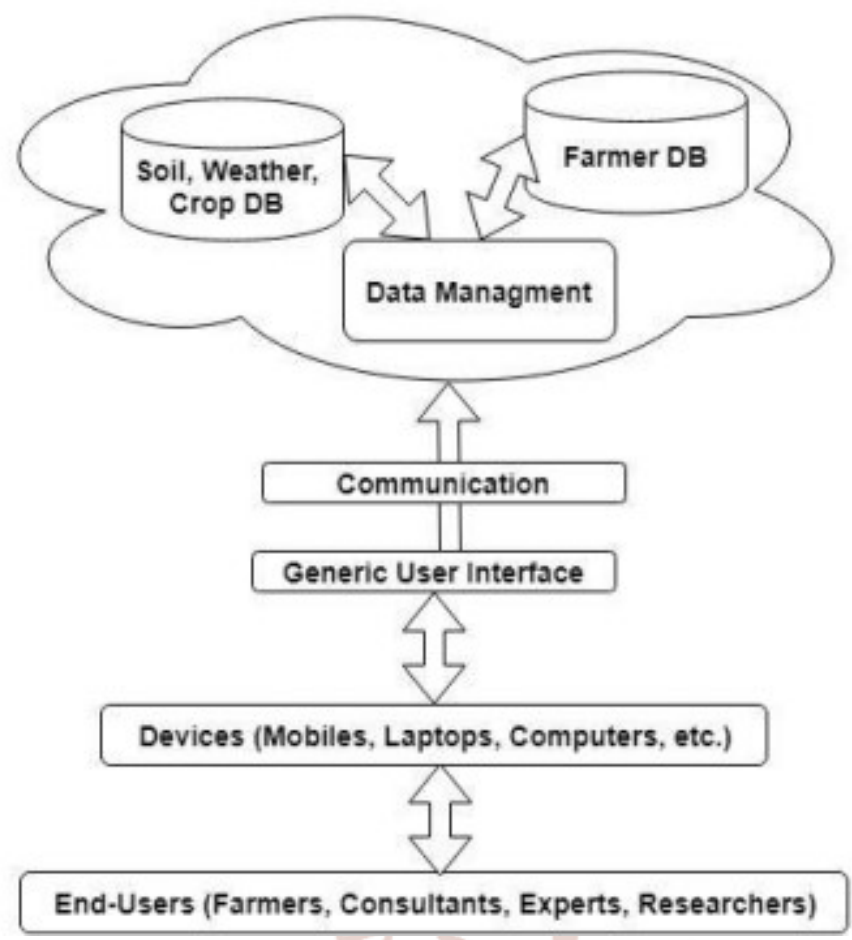

Figure 2.1: System Design

A research application which is completely based on MAD-Cloud architecture, here data (such as crop type, soil moisture, soil texture, particle density, pore space) is stored according to the coordinate (latitude and longitude), then on physical and chemical requirement related to a particular crop. Information is stacked : as methodological information, and it is refreshed by the administrator and data gathered from consistent resources like sensors, and GPS and so forth. This information is characterized in the data base as meteorological data. User can access detailed information related to the crop which is required to increase the production which the farmer wants to know such as quantity of physical requirement as well as chemical requirement, everything is available in the application [2].

For crop monitoring in the field, a cultivation application is being designed which uses remote sensor network. These systems fully equipped with two types of sensor nodes to measure humidity, temperature, and an image sensing node to compare information by taking images of crops. Parameters play an important role for taking a good decision to make the crop healthy within a period of time. The attributes are temperature, pictures and humidity. By following these methods, we can achieve high stability of sensors with low consumption of power [3], [4], [5].

$\rightarrow$ Another technique is planned and created called as the Smart Drip Irrigation System. An Android application developed for the phones is utilized to decrease the inclusion of farmers and it is utilized to control and screen the yield on the crops remotely. Water wastage can reduce with Drip Irrigation system and it works based on information from water level sensors.

Some more different sensors are used to monitor the environmental conditions as well [6].

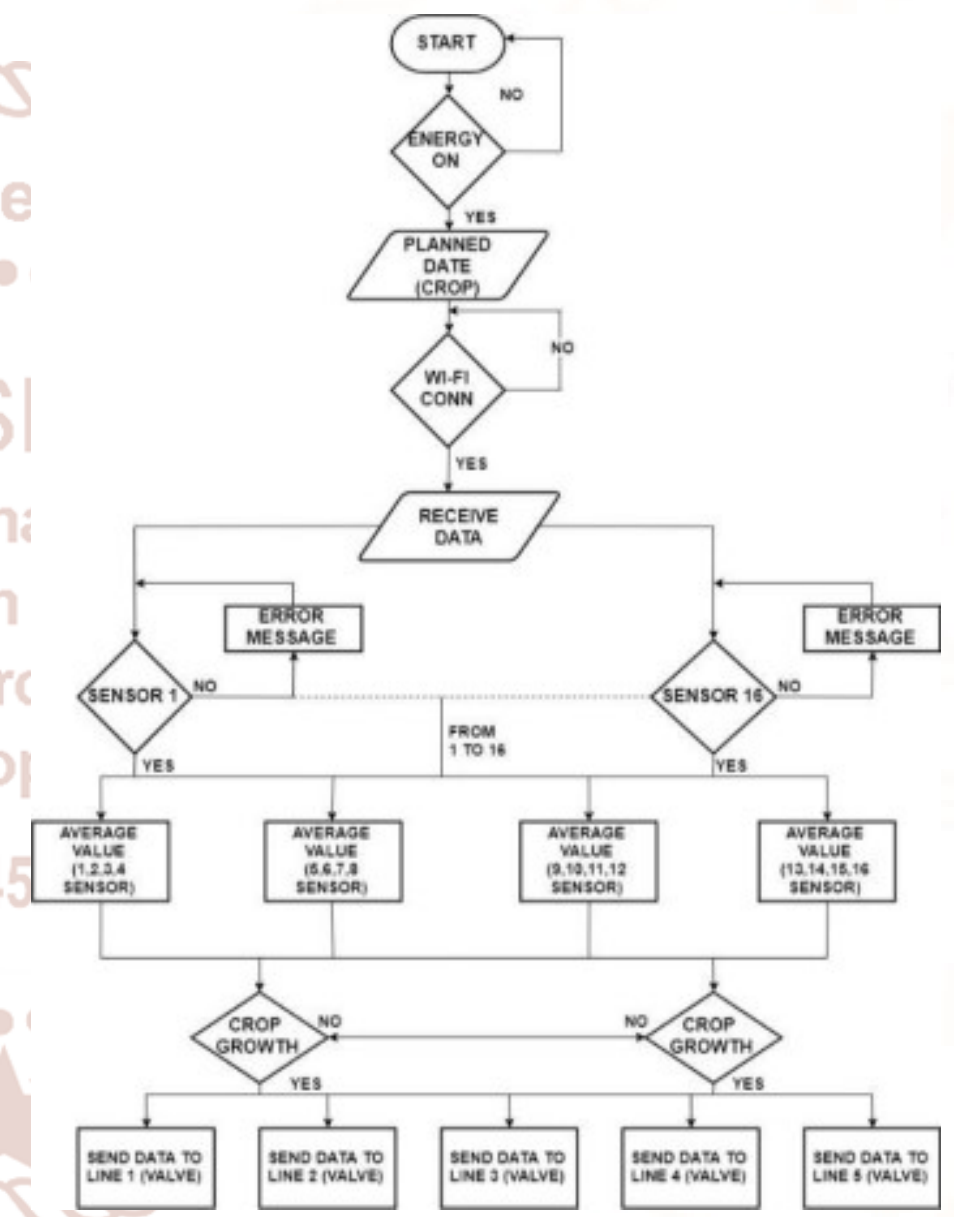

Figure 2.2: Flow diagram

In this paper, the author proposed a low maintenance and high gain Agriculture using novel Eco-friendly and Energy Efficient Sensor Technology. This paper distinctly tells us about automated monitoring of the farm and water system methods which incorporates an extensive variety of sensors to remotely detect and monitor different parameters of the ground like temperature, dampness, ripeness and controls the supply of water and manure to the land [7]. 
Smart Agriculture System based on IoT is intended to perform different farming processes like weeding, dampness detecting, spraying, winged creatures and animal frightening [8].

\section{Comparative Study}

India is one among the top countries in agriculture but in many regions unconventional methods of farming is used. The farmers are not well educated, information regarding the latest market and methods for improving the crop growth is not shared with them. This is causing farmers to grow crops in unsuitable conditions along with inefficient usage of water and unnecessary pest control. In several places where crops need water there is poor/ under usage of water which results in draught of the field whereas there is wastage of water by over-using it in many other regions. This is resulting in decline of crop growth.

By modernizing agriculture as mentioned in the methods of Chapter 3, farming and agricultural methods can be improved and efficient usage of resources can be made and also get good returns in the yield. By following the drip irrigation system, a very essential resource can be conserved. Also, farmers can be educated in using the information regarding soil type, humidity, soil moisture content, weather and suitable type of crop which can be grown and efficient kind of cultivation which can be utilized in that environment. By using several sensors and databases, farmers are aware of the various experiences of farming in a better way and to cultivate more yield. A new touch in modernizing agriculture by using latest technology like cloud computing and IoT, farmers can easily monitor their farm, control the irrigation system and with a little bit of training they can assist other farmer communities by updating the database. Moreover, this new technology can help farmers contact and communicate experts and researchers for help and information easily.

This system is aimed at enhancing the overall efficiency of Indian Agriculture operations through modernization brought about by the implementation of certain Cloud Computing, (IoT) Internet of Things and (ICT) Information Communication Technology techniques. The usage of these modern-day techniques for exchange of information and communication would significantly reduce the farmers work performed by some of its highly trained personnel thereby bringing about better management of human resources within the agriculture system.
The use of above mentioned techniques helps in conserving the energy resources of India through smart and efficient use of these resources. To illustrate a scenario, when a farmer needs to water his plants, he/she needs to do it manually which requires a lot of time and at times there might be an over usage of water which results in a waste-age of an essential resource. In such cases, smart agriculture can access information from the database such as soil moisture content, temperature, crop type which will help in watering the crops in time.

\section{Advantages}

Increase in production: Enhanced yield treatment, for example, pesticide application and direct reaping influences generation rates, watering, precise planting.

Operation costs are reduced: Automatic forms in planting, treatment and reaping can lessen asset utilization, human blunder and general cost.

Conservation of water: Climate forecasts and moisture in the soil sensors take into consideration water utilize just when and where required.

Field evaluation and accurate farming: Precisely following generation rates by the field as time flows, gives us complete information about predicting the value of the crops and yield in the near future along with the field's value.

Production insight and real-time data: Farmers can see soil moisture generation levels, intensity of the sun during the day and more continuously and remotely to quicken the process of decision making.

Monitoring the field remotely: Global or commercial and local agriculturists can screen numerous fields in various areas in and around the world with the help of the web. Choices can be set at that current moment and from anyplace.

Livestock farming is increased: Sensors and machines can be utilized to identify generation and events of the health before in creatures. Tracking the geo-fencing area can likewise enhance domesticated animals observing and administration.

Monitoring the equipment: Irrigation equipment can be checked and kept up as per generation rates, work viability and failure expectation.

Reduction of environment foot-print: All protection endeavours, for example, water use and increase in the production per field unit 
specifically influences the natural impression in a positive way.

$>$ Increase in the production quality: A proper analysis of the quality in the production and results in connection to treatment can instruct farmers to modify procedures to build on the quality of the item.

\section{Conclusion}

IoT can be implemented in many fields of agriculture and the results of this domain can be made more accurate and efficient by enabling the IoT technologies.

Firstly, energy and water are the prominent resources. These resources are highly essential and the rise or fall in price of these inputs can impact on the business continuity. A lot of water has been wasted by executing the wrong methods where plants are grown at inappropriate locations, unsuitable application methods, faulty irrigation systems, etc. To avoid these bottlenecks, various devices like pumps and boosters are used and logical techniques to calculate the correct duration, location, crop selection, volume of water etc in an efficient way.

Followed to that, the combination of IoT and agriculture can design an optimal architecture which gives good QoS, low price, better performance and complete utilization of the resources. The added advantage is that the developments can be easily understood by the farmers and can deploy them on the field with a little bit of training on the system.

The final consideration is the crop observation or monitoring which specifies the kind of raw materials used according to the condition of the soil, humidity, temperature and moisture state in the air. A variety of cameras and sensors are attached on the field which are connected to the Internet. The IoT decisions made by the Internet are collected, analysed and appropriate actions are taken on the crops by the farmers.

\section{References}

1) Seena Kalghatgi, Kuldeep P. Sambrekar, "Review: Using Cloud Computing Technology in Agricultural Development", 2015.

2) Karuna Chandraul and Archana Singh, "An Agriculture Application Research on Cloud Computing", 2013.
3) Zhao Liqiang, Yin Shouyi, Liu Leibo, Zhang Zhen, Wei Shaojun, "A crop Monitoring System Based on Wireless Sensor Network" ELSEVIER, Procedia Environmental Sciences-2011.

4) Yingli Zhua, Jingjiang Songa, Fuzhou Donga, "Applications of Wireless sensor network in the agriculture environment monitoring" ELSEVIER, Procedia Engineering Sciences-2011.

5) Shruti A Jaishetty, Rekha Patil, "IoT sensor network-based approach for agricultural field monitoring and control" IJRET: International Journal of Research in Engineering and Technology, 2016.

6) Baltej Kaur, Danish Inamdar, Vishal Raut, Akash Patil, Nayan Patil, "A Survey On Smart Drip Irrigation System", 2016.

7) Srisruthi. S, N. Swarna, G. M. Susmitha Ros, Edna Elizabeth, "Sustainable Agriculture using Eco-friendly and Energy Efficient Sensor Technology", 2016.

8) Nikesh Gondchawar, Prof. Dr. R. S. Kawitkar, "IoT based Smart Agriculture", 2016. 